\title{
Cloning, killing, and identity
}

Jeff McMahan University of Illinois at Urbana, USA

\begin{abstract}
One potentially valuable use of cloning is to provide a source of tissues or organs for transplantation. The most important objection to this use of cloning is that a human clone would be the sort of entity that it would be seriously wrong to kill. I argue that entities of the sort that you and I essentially are do not begin to exist until around the seventh month of fetal gestation. Therefore to kill a clone prior to that would not be to kill someone like you or me but would be only to prevent one of us from existing. And even after one of us begins to exist, the objections to killing it remain comparatively weak until its psychological capacities reach a certain level of maturation. These claims support the permissibility of killing a clone during the early stages of its development in order to use its organs for transplantation.
\end{abstract}

(Fournal of Medical Ethics 1999;25:77-86)

Keywords: Cloning; killing; identity; ethics; fetus

The owners of an aging dog have recently donated US $\$ 2.3$ million to researchers in order to make a clone of their pet. This and many other proposed uses of cloning are not only frivolous but are also premised on erroneous assumptions about identity. The dog owners presumably believe that the clone will be their original dog, resurrected; for one does not pay $\$ 2.3$ million in order to have a dog that is merely very similar to another. But it is confused to suppose that a clone would be identical to-that is, one and the same entity as-the individual from whom its genes were taken.

There are, however, potential uses of cloning that are quite important. When, for example, it becomes possible to clone a human being, cloning could be used to save people's lives by providing a source of tissues or organs for transplantation. A person needing a transplant could have him- or her- self cloned and then have the required tissue or organ extracted from the clone. The problem of establishing tissue compatibility would not arise.

The prospect of using cloning for this purpose has been opposed on moral grounds. Some of the objections are general and apply to all instances of cloning. These objections would apply even if the extraction of tissue from a clone would be compatible with the clone's survival and develop- ment into a mature human being. My concern, however, is with an objection that applies only if the extraction of tissues or organs would be fatal to the clone. The objection is that the clone would be the kind of entity that it would be seriously wrong to kill. Certainly if a clone of a normal human being develops normally, there will be some point at which it is seriously wrong to kill it. If, for example, the clone had to grow to be two years old in order for the needed organ to become sufficiently developed for transplantation, there would be no question of killing the child in order to take the organ.

Many critics contend that the clone is from its inception the kind of entity that it is seriously wrong to kill. Opposition to cloning for the purpose of organ procurement and opposition to abortion may thus have overlapping sources. In both cases, however, the opposition may rest on a confusion about identity - not the crude mistake of supposing a clone to be identical with the individual cloned but a subtler mistake in supposing the clone in its earliest stages to be identical with the person into whom it might eventually develop.

The cloning procedure is in principle quite simple, though there are formidable technical problems in implementing it. To produce a clone of a particular human being, one would extract the nucleus from one of that individual's cells and insert it into a human egg cell from which the original nucleus had been removed. The resulting hybrid cell would contain the individual's complete DNA code. But it would also be totipotent: it would have the potential to develop into a mature human organism. To realise this potential, it would have to be subjected to electrical pulses in order to initiate the process of cell division and then be implanted in a natural or artificial uterus.

The process of nuclear transfer parallels the process of ordinary fertilisation. The difference is that, rather than blending the incomplete genetic codes of two gametes, cloning involves the transfer of a complete genetic code into the germ plasm of an egg cell. But the product of each process is, in effect, the same: a single-celled zygote.

I will continue to refer to the product of a successful instance of nuclear transfer as "the clone". This is intended as a neutral designation for the 
entity or, as it may be, series of entities resulting from nuclear transfer at any stage in the developmental process initiated by this event. It is intended to avoid begging important questions about the nature or status of whatever is present at any point in the process: a cell or cluster of cells, a human organism, a person, or whatever.

The most important question, for our purposes, is at what point in the process initiated by nuclear transfer the clone would achieve a moral status sufficient to make it morally objectionable to kill it. As I noted, some believe that the clone would have this status from the moment the nuclear transfer was completed. Others believe that it would not achieve this status until later. Whether cloning for the purpose of procuring transplantable tissue is permissible may depend on which of these views is correct.

What might determine whether the status of the clone is such as to make it seriously objectionable to kill it? One relevant consideration is whether, at any given point between nuclear transfer and birth, the clone would be identical with-that is, one and the same individual as - the person into whom it might later develop. This depends on whether, at that point, the clone would be the same kind of entity that you and I essentially are- that is, whether it would be, as I will say, one of us.

Imagine that you were produced by cloning. One morally significant point in the process initiated by nuclear transfer in your case would have been the point at which you began to exist. Suppose, for the sake of argument, that you began to exist at some point after nuclear transfer but before birth. Between the moment of nuclear transfer and the time at which you began to exist, what I am calling "the clone" would not have been you. Suppose, for example, that you began to exist at time $t$. If someone had killed the cloned organism from which you developed prior to $t$, this would not have killed you but would merely have prevented you from existing. If, by contrast, the clone had been killed after $t$, this would have involved killing you. In general we recognise a sharp moral distinction between acts that merely prevent a person from coming into existence and acts that kill a person-for example, between contraception and infanticide. For an act that merely prevents someone from existing need not be worse for any actual person. But an act that kills someone is worse for that individual provided that the life he would otherwise have had would have been worth living. For the life that the individual will have if he is killed will be substantially less good than the life he would have had if he had not been killed.
So this could be one reason why the status ofm the clone might be such that it would not be seriously objectionable to kill it: the clone, in its early? stages, might not be anyone-might not, that is, be $\overrightarrow{\bar{F}}$ an entity of our kind, one of us. To kill it might not:be to kill someone like you or me; it might instead be only to prevent one of us from existing.

The answer to the question whether the clone would, at a certain point in its development, bed one of us would not, however, necessarily settle the question whether it would be permissible to. kill it at that point. There are several possibilities. $\overrightarrow{\vec{\omega}}$ The two most obvious are the ones we have justo noted.

(1) At a certain point in its development, then clone would be one of us-that is, would be identical with the person into whom it might $y$ develop. Therefore it would be seriouslyo objectionable to kill it at that point.

(2) At a certain point in its development, the clone would not be one of us; therefore ito․ㅡ. would not be seriously objectionable to kill it at that point.

Two other options are:

(3) At a certain point in its development, theo clone would be one of us. But, because it would lack some morally significant property⿳亠丷厂 or properties, it would not be seriously objectionable to kill it at that point.

(4) At a certain point in its development, the clone would not be one of us. But its moral status would nevertheless be such that would be seriously objectionable to kill it.

According to the third of these options, there्d might be times in my life when it would not beo seriously wrong for others to kill me-even without my consent. In the public debate abouto abortion, for example, it is often claimed that it is permissible to kill the fetus because it is not a per은 son. This is not necessarily meant to imply that the fetus is not the same individual as the persone. into whom it might develop; it might instead mears that, when each of us was a fetus, he or she lacked certain properties (for example, self으 consciousness) that are necessary for being a per ${ }^{-\omega}$ son, and that, when we lacked those properties? the moral objections to killing us were much weaker, or failed to apply altogether. Differenes explanations might be given for this. It might $\operatorname{sim}=$ ply be that, as non-persons, our moral status was lower. Alternatively, we might have lacked some necessary condition for the possession of rights Or it might be that before we became sentient we were incapable of having interests, so that ouf being killed could not have been against our interg ests before that point. I will later defend a differen explanation.

. 
According to the fourth option, even if the clone in its early stages would not be identical with the person into whom it might develop, it might nevertheless be an entity of a sort that it would be seriously objectionable to kill. It might, for example, have an intrinsic value that is independent of its being one of us. Or it might merit protection on the ground that it has the potential to become (in the sense of giving rise to the existence of) one of us.

Again, my principal concern is whether the clone, during the early phase of its existence, would be identical with the person into whom it might develop-despite the fact that the answer will not decisively establish the permissibility or impermissibility of killing the clone at that stage. At a minimum, the answer will determine whether to kill a clone during that early period would be to kill someone like you or me or whether it would be to prevent someone from ever existing.

The question: "When in the process initiated by nuclear transfer does someone like you or me begin to exist?" does not appear to raise any issues different from those raised by the question: "When in the process initiated by the fertilisation of a human egg does someone like you or me begin to exist?" The two processes run parallel even though the event that initiates each processnucleation in the germ plasm of the egg cell-is different in the two cases. Hence we need address only one question: "When do we-that is, beings of our kind-begin to exist?" If the answer for most of us is "at conception", we will have to give a different answer in the case of people produced by cloning. In these cases, our answer would presumably be "when nuclear transfer is completed". Otherwise the answer in the case of people produced by cloning should be the same as the answer in the case of people produced through fertilisation.

In order to determine when we begin to exist, it is helpful to understand what sort of being we essentially are. To say that we are essentially a certain kind of being is to say that we could not cease to be beings of that kind without also ceasing to exist. The two most common views are that we are souls, or non-material substances, and that we are human organisms. If I am essentially an incorporeal soul, I began to exist when this soul was created. If I am essentially a human organism, I began to exist when this organism-my organism-began to exist. These two views are also the only views that are compatible with the belief that we begin to exist at conception or, in the case of a clone, at the moment of nuclear transfer. For there is really no other kind of thing that might be supposed to be present immediately after conception (or nuclear transfer). If we are neither souls nor human organisms, we must have begun to exist at some point later than conception.

Suppose we are essentially souls. If the soul appears at conception, it is reasonable to suppose that it is also present upon the completion of nuclear transfer. And if it is present at either event, it seems that the soul can exist without the capacity for consciousness, for there appears to be nothing present in the womb in the early stages of pregnancy that has the capacity for consciousness. The soul, it seems, must await the development of the brain in order for consciousness to become possible. If, however, consciousness depends on the functioning of the brain, there is no reason to suppose that the soul is capable of consciousness after the brain has ceased to function at death. If the soul continues to exist after death, we should conclude that we will be unconscious throughout the afterlife, just as we were between conception and the point at which our brains began to generate consciousness. Since this is contrary to what most believers in the soul suppose, we should perhaps revise our assumptions.

An alternative conception of the soul is that the soul is, as Descartes said, a thinking thing: it essentially has the capacity for consciousnessthat is, it cannot exist without the capacity for consciousness. It is the soul, not the brain, that thinks and feels and perceives. If we conceive of the soul in this way, there are three possibilities. One is that we begin to exist at conception and are actually conscious from that point on. We are, from conception to some point late in pregnancy, like locked-in patients who later suffer retroactive amnesia, so that we cannot now remember our conscious life during that period. This is extremely implausible. The second possibility is that we begin to exist at conception and have the capacity for consciousness at that point, but cannot exercise our capacity, just as adults who are temporarily comatose have the capacity for consciousness but are prevented from exercising it. This too seems entirely ad hoc. Moreover, this understanding of our early life may also have unappealing implications for the afterlife. If the explanation of why the soul is unable to exercise its capacity for consciousness in the period following conception is related to the absence of brain function, then we should expect that the soul will also be unable to exercise that capacity in the afterlife, when brain functions have ceased.

The only reason to accept that there is anything present at conception that has the capacity for consciousness is that this is implied by our two assumptions: that the soul essentially has the 
capacity for consciousness and that it is present at conception. But the fact that these assumptions have this implication seems more obviously to be a reason to reject one of the assumptions. If we accept that the soul essentially has the capacity for consciousness, it seems more reasonable to conclude that the soul does not begin to exist until there is independent evidence of conscious life in the womb. According to this third view, even though we are souls, we do not begin to exist until at least five months after conception, when there is behavioural evidence of consciousness. Thus to kill a clone before that point would not be to kill one of us; it would instead be to prevent one of us from existing. (It would, of course, be to kill something - namely an organism not yet animated by a soul; but what that organism's moral status would be I leave open at this point.)

A view similar to this was held by Aquinas and prevailed throughout much of the Western world until about the middle of the nineteenth century. According to this view, the fetus does not come to life, or "quicken," until "ensoulment" occursthat is, when it is endowed with a soul - and it was commonly held that this does occur until well after conception. The pregnant woman's ability to feel the fetus moving was regarded as sufficient evidence that it had come to life. We still refer to the moment when fetal movement is first detected as "quickening," though we no longer understand this to be the moment when the fetus becomes alive.

It is, however, implausible to suppose that we are souls, conceived as non-material substances that essentially have the capacity for consciousness. Most of the objections to the idea that we are souls derive from our increasing understanding of the dependence of consciousness and cognition on the operations of the brain. Many are familiar and I will not rehearse them here, though I have defended some of the stronger objections elsewhere. ${ }^{1}$ Here I can only assert that, if the claim that it is wrong to kill a clone at any point after nuclear transfer depends on the idea that the clone is a soul, that claim is in a precarious position.

Turn now to the other common view of what we essentially are: that we are biological organisms of the human species. If we are human organisms, did we begin to exist at fertilisation? If so, a person produced through cloning would begin to exist at the completion of nuclear transfer.

Some have argued that the possibility that the human embryo may divide to form monozygotic twins shows that there cannot be a human organism present until fourteen days after fertilisation, when the possibility of twinning has ceased. For, if we suppose that the embryo is an organism and twinning does occur, there is no explanation off what happens to the organism. It makes no sense to suppose that the original organism survives as? only one of the twins, for the relation that it bears to each twin is exactly the same. Nor is it coherent to suppose that the original organism is identicaE with both twins, for that would imply that the twins $\overline{\bar{n}}$. are identical to each other-that is, that they are not distinct but are one thing. Finally, it would bee odd to claim that the original organism has died, for it leaves "no earthly remains". ${ }^{2}$ So, it is claimed, it is best to accept that, prior to twinning $\overrightarrow{\vec{\downarrow}}$ there was no organism there at all but merely a cell or collection of cells.

There is a reply to this argument. If an organism begins to exist at fertilisation, we can say that, if twinning occurs, that organism simply ceases to exist. Ceasing to exist through division is not the same kind of event as death and does not leave? dead remains behind. Thus, when an amoebas divides, it ceases to exist though nothing actually․ㅡ. dies.

This reply commits us to the view that, whene monozygotic twinning occurs, a human organism ceases to exist. One may be reluctant to accept thiso implication if one believes that it is always a seri-ous misfortune when an innocent human being ceases to exist prematurely; for it does not seemo that twinning involves anything regrettable. For reasons that I will later indicate, I reject the furthe $\overrightarrow{\mathcal{S}}$ assumptions necessary for the conclusion that twinning is regrettable; hence I would finc nothing embarrassing in accepting that a human organism ceases to exist whenever monozygotic twinning occurs.

Reflection on the phenomenon of twinning seems to show that, even if most of us are organ? isms that come into existence at fertilisation monozygotic twins are different. The earliest they could begin to exist is when the original embryot divides to form two new embryos.

Granting that monozygotic twins may be differ ent, is it plausible to suppose that the rest of us begin to exist at fertilisation? There are two inter pretations of the processes that occur during the fortnight following conception, before cell differ entiation begins, the "primitive streak" is formed and twinning ceases to be possible. According tळ one understanding, the successive cell divisions are all events in the history of a single individualWhen the initial single-celled zygote divides, iD becomes, or continues to exist as, a two-celled entity. The two-celled entity is simply the succes $\frac{2}{\sigma}$ sor state of the initial one-celled entity. Similarly further divisions that continue to expand the number of cells are simply further phases in the growth and development of that individual. Whefs 
each cell divides, it ceases to exist, but the individual that is constituted by the various cells continues to exist through each successive expansion of its constituent matter.

According to the alternative interpretation, when the initial single-celled zygote divides, there is nothing that continues to exist. Just as, in twinning, when the zygote divides it ceases to exist, so in the initial division the single cell ceases to exist and is supplanted by its two qualitatively identical daughter cells. Similarly, when each of the daughter cells divides, it ceases to exist and is replaced by its own two qualitatively identical daughter cells. Again, there is nothing - no individual - that persists through these transformations. Only when the cells begin to be differentiated, to take on specialised functions, and to be organised together in an integrated way do they together constitute a further individual: an organism.

If the first of these interpretations is correct, it is plausible to suppose that the zygote formed at conception is a human organism. If, furthermore, we are human organisms, then to kill any human embryo-even one formed via nuclear transfer-is to kill one of us. If, by contrast, the second interpretation is correct, a human organism does not begin to exist until at least fourteen days after conception. If this is right, to kill a human embryo during the first fourteen days after fertilisation is not to kill one of us but to prevent one of us from existing.

Which interpretation is correct? The fundamental difference is that the first holds that the clustered, proliferating cells together constitute a further individual that is distinct though not separable from them, while the second interpretation denies this. The case for the first interpretation depends on the observation that the cells are bundled together within a single membrane (the "zona pellucida") and eventually begin to take on specialised tasks in the constitution of the organism and its prenatal environment. Unlike a series of amoebas, where division produces daughter cells that may wander off to lead quite independent lives, the embryonic cells and their progeny form a discrete unit. That unit, it is claimed, is the organism.

The case for the second interpretation is that, during the first two weeks after conception, the cells are only loosely grouped within the zona pellucida. They are independent and uncoordinated and, at least until the eight-cell stage, each is "totipotent"- that is, capable, if separated from the others, of developing into, or giving rise to, a complete adult organism. It is this lack of integration among the cells that suggests that they do not together constitute an organism.
Consider, as an analogy, an island on which there are people. Suppose these people are entirely unrelated: each came to the island independently, lives in solitude with no communication or cooperation with the others, and is even unaware of the existence of most of the others. It seems clear that these individuals do not together constitute an individual of any substantial sort. If, by contrast, various relations obtain among them-if, for example, they are related genealogically, speak the same language, follow the same customs, cooperate together in complex ways, and so on-then it is plausible to suppose that they together constitute a distinct individual: a nation, for example.

If the zygotic cells are relevantly like the inhabitants of the island in the scenario in which they are unrelated, it seems that the cells do not constitute an individual and, a fortiori, are not an organism. If, instead, they are relevantly like the complexly related inhabitants, it is more plausible to regard them as together constituting an organism.

It seems to me more plausible to regard the cells during the first fourteen days as insufficiently closely related to constitute an organism. Yet I would not claim to be right about this; for it seems that there is no deep truth here to be discovered. ${ }^{3}$ Consider again the analogy with nations. A nation is nothing but a set of people related to one another in certain ways. We accept that there can be borderline cases in which it is indeterminate whether a group of people are sufficiently related in the relevant ways to constitute a nation. The case is the same with organisms. An organism is nothing more than a collection of cells related in various complex ways. Thus we should accept that there can be borderline cases in which it is indeterminate whether a collection of cells constitutes an organism.

If there were no instances of indeterminacy, there would have to be a precise point in the process of cell division initiated by fertilisation at which an incremental increase in the unifying relations among the cells would make the difference between there being an organism and there not being one. That is surely implausible. Instead, it seems that, if an organism does not begin to exist at fertilisation, there is no precise point at which it does begin to exist. There is a brief period following fertilisation in which no organism exists, followed by a brief period during which it is indeterminate whether the proliferating cells constitute an organism. Eventually the cells are sufficiently unified that it is clear that they form an organism.

The problem is that our concept of an organism is not precise enough to allow us to identify an 
exact point at which cellular organisation has become sufficiently integrated that an organism has begun to exist where previously there was only a collection of cells. At a certain period during the process initiated by fertilisation, we could know everything that is happening at the cellular level without this being sufficient to determine whether or not the cells together constitute an organism.

If this is right-that the issue is merely a conceptual one-it is hard to see how anything of deep and intrinsic moral significance could depend on it. Yet, if we are organisms and it matters morally whether to kill an embryo is to kill one of us, then it may matter greatly whether the embryo is an organism. I will suggest a response to this problem later in the paper.

In summary, although it is not unreasonable to believe that an organism begins to exist at fertilisation, it is more plausible to suppose that a human organism does not begin to exist until about fourteen days after fertilisation. If an organism does not exist until a fortnight after conception, and if we are organisms, then to kill an embryo prior to that point would not be to kill one of us but would merely be to prevent one of us from existing. If this is right, it removes a major objection to killing a cloned embryo during the fortnight following nuclear transfer. And there are valuable therapeutic uses to which embryonic tissues could be put. But these uses are limited. If we are organisms that begin to exist around fourteen days after fertilisation, and if it is seriously objectionable to kill one of us for the purpose of extracting transplantable tissues, then the killing of cloned embryos will have to be confined to the fortnight following nuclear transfer and the use of cloning as a source of transplantable tissue will be severely restricted. In order for it to be acceptable to kill a clone at a later stage of development, one of two claims must be true: either we are not essentially human organisms or the moral objections to killing people like you and me do not apply, or apply only very weakly, in the very early stages of our existence. I will argue that both these claims are true.

There are various arguments against the view that we are essentially human organisms. I will present, in abbreviated form, two that seem most persuasive. The first appeals to an example drawn from science fiction. Suppose that one's entire brain were extracted from one's body and transplanted into the cranium of one's identical twin, whose own brain had just been removed. Most people believe that one would continue to exist in what was formerly the body of one's twin. One would then occupy, and animate, a different organism. There are various things that might

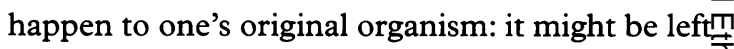
to die; it might receive a brainstem transplant thereby remaining alive though incapable of supporting consciousness; its functions might be sustained indefinitely with the aid of artificial life $=\overrightarrow{0}$ support systems; or it might have the whole of someone else's brain transplanted into it, thereby not only remaining alive but also becoming host to an entirely different person. Whichever course ofes events we imagine happening, one's originalorganism would continue to exist (as a corpse, ina persistent vegetative state, or whatever) on onew bed in the operating theatre while one would one $\frac{\text { s }}{3}$ self regain consciousness in a different organismo on another bed. There would then be two separatê and distinct entities: oneself and one's originaliv organism. But, if one would not then be identical $\mathrm{V}$ with that organism, it follows that one never was? identical with it. Generalising, we can concludethat none of us is identical with his or her physicalo organism.

Some will object to this argument on the $\overrightarrow{0}$ ground that our intuitions about cases drawn frome science fiction are unreliable. The second argu-C ment cannot be rejected on that ground. This argument appeals to the phenomenon known as "dicephalus," in which a human embryo divideső incompletely, resulting in twins conjoined below the neck. In dicephalic twinning, as in other forms $\overrightarrow{\vec{\sigma}}$ of twinning, it is clear that there are two people. In 3 one contemporary instance, Abigail and Brittany? Hensel present a spectacle of two heads sprouting. from a single torso; yet no one doubts that they are separate and distinct little girls. ${ }^{4}$ Each has her own:private mental life and her own character, each 3 . feels sensations only on her own side of the body and each has exclusive control over the limbs on her side. But, although Abigail and Brittany areo two different persons, there seems to be only ones organism between them. If so, then neither girl is identical with that organism. For they cannot bothn be identical with the organism, as that would? imply that they were identical with each other Nor is it plausible to suppose that one of them is identical with the organism while the other is? some sort of parasite hosted by the organism. (Even if this understanding were plausible, ite would implicitly concede that there is at least one person who is not an organism.) So it seems that we should accept that neither is identical with the

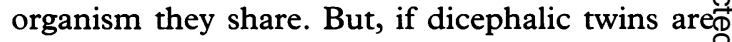
not human organisms, this strongly suggests that none of us is an organism. For, despite their anomalous physical condition, there is no reasono to suppose that dicephalic twins are fundamentally different types of being from the rest of us. 
Those who hold that we are essentially human organisms seem to have only two options. One is to claim that, because dicephalic twins constitute a single human organism, that organism can be at most one person-a person with a divided mind, or perhaps a person with two minds. This response denies that the Hensel twins are different persons. It treats them as analogous to the severed hemispheres in a commissurotomy patient: distinct centres of consciousness but together constitutive of a single person. This seems obviously unacceptable.

The other option is to claim that dicephalic twins are actually two distinct though overlapping organisms. This understanding is entirely compelling in the case of conjoined twins who are only superficially melded (and therefore potentially separable), as well as in cases in which there is only a limited sharing of organs or parts but extensive duplication of others. It is substantially less plausible, however, when, there is only very limited duplication of organs. Although the Hensel twins have two hearts and two stomachs, they otherwise share a single set of organs wrapped in a single skin, sustained by a single coordinated system of metabolism, served by a single integrated circulatory system, protected by a single immune system, and so on. These systems and the processes they sustain together constitute a single biological life, despite the fact that various aspects of this life are jointly governed by two brains. It is a single biological life that supports the existence of two distinct persons. (Recorded cases of dicephalus show varying degrees of duplication and it seems possible that there could be an even purer case than that of the Hensel twins in which there would be virtually no duplication of organs below the neck.)

These arguments strongly challenge the idea that one is the same thing as one's organism. If, however, we are neither souls nor human organisms, what are we? The most plausible view, I believe, is that we are essentially embodied minds. According to this view, I began to exist when the brain in this body-my body-first acquired the capacity to support consciousness. My continued existence has depended on the physical and functional continuity of enough of this brain to be capable of continuing to support consciousness. I will cease to exist when those areas of my brain in which consciousness is realised irreversibly lose the capacity to generate consciousness.

There is no space to argue for this view here, though I have sought to defend it elsewhere. ${ }^{1}$ If it is correct, we do not begin to exist until approximately 28 to 30 weeks after fertilisation- assuming that current estimates of when in the course of fetal development consciousness becomes possible are roughly accurate. This, of course, is well after our organisms begin to exist. But, if one is not identical with one's organism, it is perfectly possible that one began to exist after it did, and equally possible that one may cease to exist before it does, or even before it dies.

A case can be made for the permissibility of killing a developing human organism prior to the point at which one of us begins to exist in association with it. For this would not be to kill one of us but only to prevent one of us from existing. As I acknowledged earlier, of course, there might be moral objections to killing a developing human organism even if this would not be to kill someone like you or me. Again, there is no space to consider this possibility in detail. Here I can only note that I do not believe that there can be serious objections. There is no more reason to suppose that an unoccupied organism has interests or rights than there is to suppose that a plant does. It does not even have any significant potential. (It may have the potential to cause a person to exist, just as a sperm and an egg do; but, again like the sperm and egg, it does not have the potential to become a person, in the sense of "becoming" that presupposes identity. For, if my earlier arguments are right, persons are never identical with mere organisms.) It may, admittedly, have intrinsic value by virtue of the marvellously intricate organisation of its myriad parts; but it should have no more value of this sort than a comparably complex non-human organism.

If it would be permissible to kill a human organism prior to the point at which that organism would support the existence of one of us, killing a clone in order to obtain transplantable tissue would be permissible up to about the seventh month of pregnancy. This would allow for a moderate degree of differentiation and maturation of tissues and organs, making cloning a potentially much richer source of transplantable tissue than it would be if a clone could permissibly be killed only during the fortnight following nuclear transfer. A further possibility, of course, would be to intervene to prevent the clone from ever developing the capacity for consciousness. One might, for example, deliberately create an anencephalic clone by suppressing the action of the genes responsible for the development of the cerebral hemispheres. In so doing, one would prevent the cloned organism from ever giving rise to the existence of someone like you or me. Because it would be a permanently unoccupied organism, it might permissibly be allowed to develop even further before its organs were extracted for transplanta- 
tion. There are various objections to this proposal, among which is the claim that it is wrong to create or tamper with the nature of a human being without appropriate regard for the good of that human being. It is, however, questionable whether this sort of consideration applies to the creation of mere organisms - that is, organisms that never support the existence of a mind (or self or person). Again, there is no space to pursue this here.

I have suggested that killing a cloned organism might be permissible up to the point at which one of us begins to exist in association with it, on the ground that this would be merely to prevent one of us from existing. But there is a general objection to this kind of claim. Suppose we can identify the point, subsequent to conception, at which we-or entities of our kind-begin to exist. Call this point $t$. The suggestion is that, prior to $t$, there is no one for whom it is worse if a cloned organism is killed. But, after $t$, there is an individual present that, if it lives, will become (that is, will be identical with) a person like you or me. To kill that individual would be worse for it. For its life as a whole if it is killed will be a worse life than the longer life it would have if it were not killed. Indeed, if the badness of death varies with the magnitude of the loss suffered by the victim, death immediately after one has begun to exist must be the worst death one can suffer; for one thereby loses the whole of a human life rather than only the later stages of a life. This suggests, however, that while to kill a clone immediately prior to $t$ would be innocuous, to kill a clone just after $t$ would be to inflict one of the gravest harms that it is possible for us to suffer. Yet, intuitively, there does not seem to be any point at which killing a fetus (cloned or otherwise) ceases to be innocuous and suddenly becomes murderous instead. Fetal development is a smoothly continuous process; it seems impossible to identify any event in this process that is significant enough to make the difference between permissible killing and murder. Intuitively, the degree to which killing is morally objectionable seems to increase slowly and gradually, in a way that corresponds to the process of fetal maturation.

How can we explain and justify this common intuition? I believe the best explanation lies in understanding the significance of the way in which the fetus would be related to itself in the future. To see this, we must begin by noting that each of us has a special sort of concern for his or her own future. We anticipate our own experiences in a way that is different from our attitudes to other people's future experiences. As one writer observes, "we all know the difference between fearing our own pain and fearing the pain of someone else. The difference here consists not in
degree-I may care more about the pain of myM beloved than about my own-but in kind". ${ }^{5}$ Let us call this special kind of concern about the future? "egoistic concern".

It has always been assumed that the basis for egoistic concern is identity-that the mere facto that someone will be me gives me a reason to cares in an egoistic way about what will happen to that person. This assumption has, however, been challenged by Derek Parfit. ${ }^{6}$ His argument appeals to a hypothetical case-the case of "Division"-in which a person divides into two people. Suppose $\overrightarrow{\vec{\omega}}$ for example, that the cerebral hemispheres of person, A, are divided and separately transplanted into the bodies of his identical triplet brothersin whose cerebrums have been destroyed anf removed but whose brainstems and bodies are $y$ intact and functional. Following the transplanto operations, two people, $\mathrm{B}$ and $\mathrm{C}$, will come toconsciousness. Each will have most of A's memo- $\rightarrow$ ries, beliefs, values, and character traits, and each will believe himself to be A. But because there are two such people, they cannot both be A, for thate would imply that they are identical with each other (that is, that they are one and the same per-o son). Parfit contends that the logic of identity forces us to conclude that neither is $\mathrm{A}$ - that $\mathrm{A}$ has ceased to exist. Notice, however, that if only one of these people were to exist, (if, for example, one of the transplant operations had failed), most of us believe that that person would be A. For the relas tion between $\mathrm{A}$ and $\mathrm{B}$, for example, contains al that is necessary for identity. (That relation is nos sufficient for identity because it can hold between $A$ and more than one person.) Notice, too, that if only B were going to exist, A would have reason to care in an egoistic way about B. The basis for ego@ istic concern is present in the relation between $A$ and $\mathrm{B}$. And this fact (unlike the claim about iden을 tity) is unaffected by the additional presence of $C_{8}$ Indeed, if the basis for egoistic concern is presene. in the relation between $A$ and $B$, it must also bo present in the relation between $\mathrm{A}$ and $\mathrm{C}$, for the two relations are substantially the same. Thus $A$ has reason, prior to the operations, to be egoistically concerned about both B and C; but he will be neither. Hence identity cannot be the basis for egoistic concern.

What is the rational ground of egoistic concern about the future, if it is not identity? In practice each of us is egoistically concerned only aboug him- or her- self. Unless this tendency is radically, misguided, the relations that ground egoistic con $\frac{2}{6}$ cern must coincide with identity in most cases The best explanation for this is that the basis fof egoistic concern at least includes those relations that are constitutive of personal identity in the 
normal case. According to the view I cited earlier, the relations that are constitutive of our identity over time are physical and functional continuity of certain parts of the brain. I believe that the presence of these relations is a sufficient condition for the rationality of at least a minimal degree of egoistic concern about the future. But I follow Parfit in believing that another component of the basis of egoistic concern is psychological connectedness. A person at an earlier time and a person at a later time are psychologically connected if there are direct connections of memory, belief, desire, etc between them-for example, if $B$ remembers something that A experienced. Psychological connectedness is a matter of degree: generally there are more direct psychological connections over shorter periods than over longer periods. And the degree of connectedness also varies with the degree of development of an individual's psychological capacities: thus there are more psychological connections between a person now and himself a month ago than there are between a dog now and itself a month ago. I follow Parfit in believing that, if the relations that ground egoistic concern are a matter of degree, then egoistic concern may also rationally be a matter of degree. Thus, if psychological connectedness is at least part of the basis of egoistic concern, an individual may rationally have a weaker degree of egoistic concern about himself in the future when the degree to which he would be psychologically connected to himself in the future would be diminished.

If identity is not the basis for egoistic concern, it is possible that egoistic concern can be rational in the absence of identity. In Division, for example, A may rationally be concerned in an egoistic way about both B and C. It is also possible, though I have doubts about this, that there could be identity but no basis for egoistic concern. A less radical possibility is that just suggested: that there could be identity but only a weak basis for egoistic concern. This, I will suggest, is true in the case of the relation between a fetus and the person it might later become.

One problem, of course, is that a fetus lacks the capacity to be concerned about itself in the future. This requires the introduction of a new concept. Let us say that an individual has an egoistic interest in some future possibility if it is rational for that individual to be egoistically concerned about that possibility or if it would be rational for that individual to care in an egoistic way about that possibility if the individual could conceive of it. It is important to note that an egoistic interest is different from an interest as ordinarily understood, for the latter presupposes identity whereas the former does not. One's interests correspond to what is better or worse for oneself, taking account of one's life as a whole. But one's egoistic interests may in principle range outside of one's own life (as in the case of Division); or they may be weaker than one's interests, if the relations that ground egoistic concern are weak.

The claim I wish to make can now be articulated by saying that, even though death would be much worse for a fetus than continuing to live (and therefore might be said to be greatly against its interests), its egoistic interest in continuing to live is comparatively weak. For the strength of an individual's egoistic interest in a set of future goods is a function both of the amount of good he can anticipate in an egoistic way and of the strength of the relations that make his egoistic concern for those goods rational. In the case of the fetus, the amount of good that its future life would contain if it were not to die is very great. But at least some of the relations that bind the fetus to itself in the future in the way that makes egoistic concern rational are present only to a very weak degree. For there would be virtually no psychological connections between the fetus and the person it might later become. It is the fact that the fetus is thus psychologically cut off from itself in the future-so that its future is, in a figurative sense, relevantly like someone else's future rather than its own-that it matters less, from the fetus's present point of view, whether it lives to have that future or not.

If this is right, it provides an explanation of why there is no point at which killing a fetus immediately shifts from being innocuous to being gravely wrong. In the early stages of pregnancy, before one of us begins to exist in association with the developing organism, there is no one who would be affected for the worse if the organism were killed. Thus the killing of a clone in the early stages of its existence can be regarded as largely innocuous. After one of us begins to exist, however, there is someone for whom death would be worse, so that to kill that individual would be to harm it. Yet, because of the primitive nature of the fetus's mental life, it is psychologically cut off from its own future and thus may have only a weak egoistic interest in continuing to live. Because of this, the moral objection to killing it may be comparatively slight. As the fetus matures, however, its mental capacities are increasingly enhanced, thereby establishing the potential for more extensive psychological connections with itself in the future. As its mental life becomes richer and more unified, the strength of its egoistic interest in continuing to live increases, and the moral objection to killing it becomes correspondingly stronger. In 
short, it is the fact that the fetus's egoistic interest in continuing to live increases in strength as its psychological capacities mature that explains why killing becomes more morally serious as fetal development continues.

These claims apply even if we are essentially human organisms that begin to exist at conception. For, if psychological connectedness is part of the basis for rational egoistic concern about the future, we would, at conception, have only a weak egoistic interest in continuing to live, for at that point we have no psychological connections with ourselves in the future. This would explain why, even if we are organisms, early spontaneous abortions are not tragedies. It would also explain why most of us do not regard abortion as morally comparable to the killing of a child or adult.

The fact that we may reach similar conclusions whether we assume that we are embodied minds or human organisms illustrates an important point. This is that, if identity is not the basis for egoistic concern, our understanding of what we are and when we begin to exist has substantially less practical significance.

The skeptical reader may wonder why our moral concern should be guided by an individual's egoistic interests rather than by what would be better or worse for that individual. I have conceded that, if we consider the fetus's life as a whole, it is clear that death would be much worse for it than continuing to exist. Why should not this fact-rather than the fact that the fetus's egoistic interest in continuing to live is weak-determine the morality of killing the fetus? This is a difficult question, but there are several points that may be briefly made in reply. An individual's interests and his egoistic interests normally coincide. It is only rarely, in cases in which the basis of an individual's egoistic concern about the future is unusually weak, that they diverge. Where they diverge, the egoistic interest seems prudentially and morally more significant. In the case of the fetus, for example, it is the egoistic interest that explains our sense that its death matters less than the death of an older person, which in turn supports the view that killing the fetus would be less objectionable. Division is another case in which an individual's interests diverge from his egoistic interests. Here too the egoistic interest seems to capture what is more important. It is against A's interests to divide. If he divides, he will cease to exist; there will be no further good in his life. Yet it may be egoistically rational for him to want to divide. If he divides, he will be connected in the way that grounds egoistic concern to two future lives rather than one.
I do not claim, however, that killing is wrongn only because, and only to the extent that, $\mathrm{i}$. frustrates the victim's egoistic interest in continu? ing to live. Where the killing of persons is concerned, the frustration of the victim's egoistic interests is only one factor that contributes tof making killing wrong. There is another dimensioro to the morality of killing that is concerned with the respect that we owe to other persons as our morad equals. It is doubtful, however-though I cannof defend this claim here-that these further consid? erations apply in the case of individuals, such ast fetuses, that lack self-consciousness and autonomy. ${ }^{7}$ If this is right, the moral objection t $\overline{\mathrm{Q}}$ killing a fetus should be commensurate, other things being equal, with the strength of the fetus's egoistic interest in continuing to live.

In summary, I suggest that the killing of a clong in the early stages of its development is permissi? ble on the ground that there is as yet no one there who would be harmed by being killed. Later, afte? one of us begins to exist in association with the cloned organism, there is someone who would bee affected for the worse by being killed. But the moral objection to killing that individual is initiall relatively feeble owing to the extreme weakness of the individual's egoistic interest in continuing to live. Killing becomes increasingly objectionable a the individual's psychological capacities develop? but may remain permissible for some time (perhaps until around the time of birth) provided that there is a sufficiently significant end that might thereby be achieved. Saving a person's life is such an end.

\section{Acknowledgement}

I am grateful to David McCarthy and Juliai Savulescu for comments on this paper.

Feff McMahan is Associate Professor of Philosoph University of Illinois at Urbana, USA.

\section{References} 1 McMahan J. Killing at the margins of life. New York: Oxforg

2 Kuhse H, Singer P. Individuals, humans and persons. In: Singes $\mathrm{P}$ et al, eds. Embryo experimentation. Cambridge: Cambridge University Press, 1990: 67.

3 The following remarks parallel one of Derek Parfit's arguments for a reductionist view of persons. See Parfit P. Reasons and per sons. Oxford: Oxford University Press, 1984:211-12.

4 Miller K. Together forever. Life 1996 Apr: 44-56.

5 Schechtman M. The constitution of selves. Ithaca: Corne University Press, 1996:52.

6 See reference 3:ch 12 .

7 See McMahan J. Killing and equality. Utilitas 1995;7:1-29.

8 This article was stimulated by my reading a provocative unpublished paper by Julian Savulescu. The article also drang heavily on ideas developed in more detail in Killing at the mat gins of life: see reference 1 . 